\title{
Electron microscopic evidence of flagella and pili on Legionella pneumophila
}

\author{
FG RODGERS, PW GREAVES, AD MACRAE, AND MJ LEWIS \\ From the Public Health Laboratory, University Hospital, Queen's Medical Centre, Nottingham \\ NG7 $2 U H, U K$
}

SUMMARY Twenty-one strains of Legionella pneumophila, representing the six known serotypes of the organism, cultured on various bacteriological media and in the yolk sacs of fertile hens' eggs were examined by negative stain electron microscopy for flagella and pili. These appendages were usually observed after cultivation on media capable of inducing an early profuse growth of the organisms.

Legionella pneumophila, a recently reported bacterial species, ${ }^{1}$ is the causative organism of an acute form of lobar pneumonia known as Legionnaires' disease, so called after an outbreak that followed an American Legion Convention in Philadelphia in $1976 .{ }^{2}$ From postmortem lung tissue or culture on bacteriological media the organism appeared characteristically to be a small bacillus with properties resembling those of other Gram-negative bacteria. ${ }^{3-5}$ Its size is approximately 0.3 to $0.5 \mu \mathrm{m}$ by 1 to $3 \mu \mathrm{m}$, but longer filamentous forms are common. Organisms can be specifically identified from postmortem tissues, infected yolk sacs of fertile hens' eggs, and bacteriological media by immunofluorescent antibody staining $^{6}$ and immunoferritin electron microscopy. ${ }^{7}$ By gas-liquid chromatography the bacteria show a characteristic fatty acid profile. ${ }^{8}$ Strains of legionellae have also been recovered from environmental sources. 910

Early studies of the organism after growth on less satisfactory bacteriological media such as MuellerHinton agar did not reveal the presence of flagella or pili (fimbriae) ${ }^{11}$ or indicate motility. On new media, ${ }^{12}{ }^{13}$ which give a more rapid and profuse growth of the organisms, some strains were shown by optical microscopy ${ }^{14}$ to possess flagella. Similarly, flagella and fimbriae or pili were evident by electron microscopy. ${ }^{15}$ This report confirms and amplifies the finding of such appendages on strains of legionellae cultured on various bacteriological media and in egg yolk sacs.

Received for publication 8 May 1980

\section{Material and methods}

ORGANISMS AND CULTURE MEDIA

Twenty-one strains of $L$. pneumophila were examined. These consisted of (a) serogroup 1: Philadelphia 1 and 2, Pontiac 1, Cambridge 1, Washington 1, Nottingham N/P/1, N/M/2, N3, N/P/4, N5, N6, N7, N8, N9, Bloomington 1, and Corby 1 ; (b) serogroup 2: Togus 1; (c) serogroup 3: Bloomington 2; (d) serogroup 4: Los Angeles 1; (e) serogroup 5: Cambridge 2; and $(f)$ serogroup 6: Oxford 1. The strains from environmental sources were Bloomington 1 and 2 and Corby 1 , the others having been recovered from clinical material. In addition, the Oxford 1 strain was isolated from both environmental and clinical specimens. ${ }^{10}$

Strains were cultured on Mueller-Hinton agar supplemented with $1 \%$ haemoglobin and $2 \%$ Iso Vitalex, CYE agar, ${ }^{12}$ enriched blood agar, ${ }^{13}$ and enriched broth medium containing: (Difco) proteose peptone $1.5 \%(\mathrm{w} / \mathrm{v})$; yeast extract $0.5 \%(\mathrm{w} / \mathrm{c})$; panmede liver extract $0.25 \%(\mathrm{w} / \mathrm{v})$; sodium chloride $0.5 \%(\mathrm{w} / \mathrm{v})$; L-cysteine hydrochloride $0.04 \%(\mathrm{w} / \mathrm{v})$; and soluble ferric pyrophosphate $0.0125 \%(\mathrm{w} / \mathrm{v})$. In addition, a modified CYE agar containing $0.3 \mathrm{~g}$ $(\% \mathrm{w} / \mathrm{v})$ Lab Lemco beef extract was used. Cultures were incubated at $36^{\circ} \mathrm{C}$ in a humid atmosphere containing $5 \% \mathrm{CO}_{2}$ until, on solid media, individual colonies appeared or, in broth, a visible opacity occurred. The duration of incubation varied with the culture medium, being longest with Mueller-Hinton and CYE agar (five to seven days) and shortest with enriched blood agar (two to three days). Cultures on 


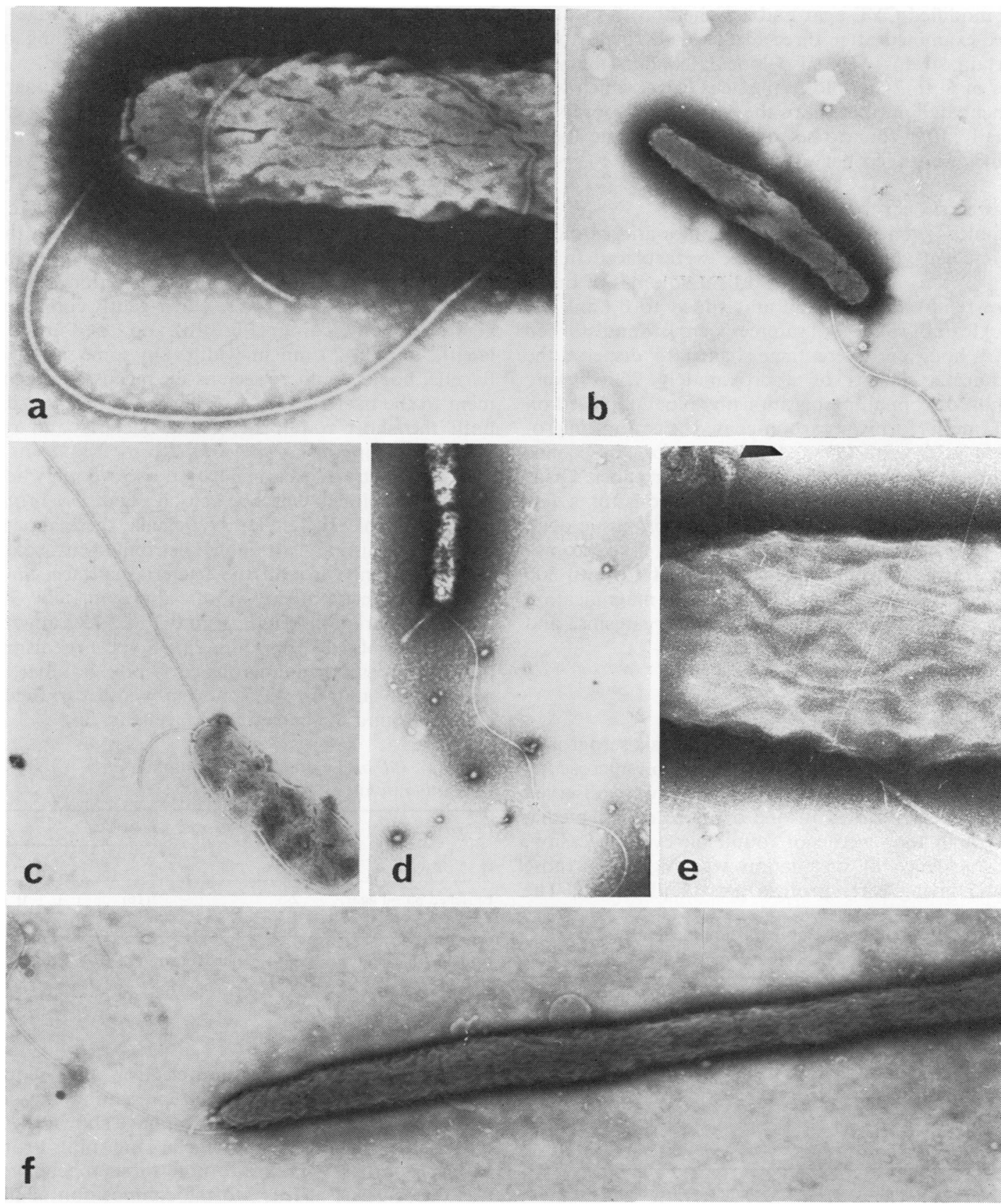

Fig. 1 Flagella on Legionella pneumophila, negatively stained with $1 \%$ phosphotungstic acid, pH 6.5. (a) Part of Cambridge 2 organism from enriched blood agar medium. Note insertion of single flagellum in the polar region of the organism. $(\times 66000) .(b)$ Cambridge 1 organism from enriched blood agar medium showing single subpolar flagellum. ( $\times 20000)$. (c) Partially plasmolysed organism of Nottingham N/9 strain from enriched broth medium. Note two polar flagella, one curved (broken), one straight. $(\times 14400) .(d)$ Dividing organism of Nottingham N/8 strain from enriched broth medium showing single undulating flagellum. $(\times 14400) .(e)$ Flagellum with attachment hook (arrow) from Togus 1 strain grown on modified CYE agar. $(\times 80000)$. $(f)$ Filamentous organism of Cambridge 1 strain with single polar, slightly curved, flagellum. From enriched blood agar. (This flagellate organism was $49 \mu \mathrm{m}$ in length. $)(\times 22500)$. 
the modified CYE agar and enriched broth medium were examined after three to five days' incubation. Certain strains were also inoculated into the yolk sacs of 6- to 7-day-old fertile hens' eggs, which were reincubated until death of the embryo was observed, usually after four to six days. The yolk sac membranes were then harvested.

\section{ELECTRON MICROSCOPY}

Samples taken from discrete colonies and as pieces of infected yolk sac membrane were placed in $\mathbf{0} \cdot \mathbf{1}$ $\mathrm{ml} 1 \%(\mathrm{v} / \mathrm{v})$ formol-saline; $0 \cdot 1 \mathrm{ml}$ volumes of broth were removed by pipette and added to $0 \cdot 1 \mathrm{ml} 2 \%$ $(\mathrm{v} / \mathrm{v})$ formol-saline. All samples were left undisturbed for 1 hour and were then shaken to disperse the organisms. Drops of approximately $25 \mu \mathrm{l}$ were removed from all preparations by pipette, placed on 400 mesh formvar-carbon-coated electron microscope grids, and allowed to stand for 30 seconds before the excess was drained with filter paper. Grids were negatively stained by the addition, for a few seconds, of 1 drop $1 \%$ (v/v) phosphotungstic acid, pH 6.5. After they had been blotted dry, the prepared grids were examined in an AEI Corinth 500 or Jeol $100 \mathrm{C}$ electron microscope; a magnification of $\times 5000$ was used to identify the organisms, and $\times 25000$ to search for flagella and pili.

\section{Results}

Twenty-one strains of legionellae from six serogroups were examined by negative stain electron microscopy after cultivation, as indicated. Flagella were observed on all strains grown in one or more of the media. Although they were not found on every occasion, the incidence of flagellation was higher in those media giving early profuse growth (Table 1). The

Table 1 Flagella on Legionella pneumophila after cultivation in vitro

\begin{tabular}{|c|c|c|c|c|c|c|}
\hline \multirow[t]{2}{*}{ Culture medium } & \multirow{2}{*}{$\begin{array}{l}\text { Incubation period } \\
\text { (days) }\end{array}$} & \multicolumn{5}{|c|}{ Serogroup } \\
\hline & & 1 & 23 & 45 & 5 & 6 \\
\hline Mueller-Hinton agar & $5-7$ & $3(10)$ & 11 & $0 \mathrm{I}$ & NT & \\
\hline CYE agar & $5-7$ & $4(10)$ & 00 & $0 \mathrm{P}$ & NT & \\
\hline CYE agar + beef extract & $3-5$ & $8(10)$ & 11 & $1 \mathrm{~N}$ & NT & \\
\hline Enriched blood agar & $2-3$ & $14(16)$ & 11 & 11 & 1 & 1 \\
\hline Enriched broth medium & $3-5$ & $13(16)$ & & & 0 & $i$ \\
\hline Yolk sac membranes & 4-6 & $2(3)$ & 11 & i I & NT & 0 \\
\hline
\end{tabular}

Numbers in parentheses indicate the number of strains tested; serogroups 2-6 one strain of each examined.

NT $=$ not tested.

Nottingham $\mathrm{N} / \mathrm{M} / 2$ and Washington 1 strains were deficient in flagella from the enriched blood agar but positive from enriched broth medium. The reverse effect was observed for the Philadelphia 1, Notting- ham N3 and N/P/4, Togus 1 , and Cambridge 2 strains. Examination of agar plates for gliding or swarming motility was negative for all strains.

Even with careful manipulations and stationary fixation the flagella, unsheathed in structure, were often dissociated from and distributed around the bacteria. When attached to organisms, they were mainly single, in a polar (Fig. 1a) or subpolar (Fig. 1b) arrangement, though occasionally in pairs (Fig. 1c). The polar arrangement was more common than the subpolar, and, due to folding of the flagella, it was often difficult to determine precise insertion points. Flagella from all strains were either gently curved or vigorously undulating (Fig. 1d), up to $8 \mu \mathrm{m}$ in length, and 14-20 $\mathrm{nm}$ in width. On some isolated flagella, hooks could be seen as the means of attachment to the bacteria (Fig. 1e). They were present on both the short rod form of the bacteria and on filamentous organisms (Fig. 1f).

Of the 21 strains examined, 14 possessed pili when grown on either enriched blood agar or broth medium (Table 2). Unlike the flagella, these appendages were usually straight, distributed in small numbers evenly around the bacterial surface, and, although consistent in width-approximately 5.8 $\mathrm{nm}$ - they varied in length from 0.3 to $2.25 \mu \mathrm{m}$ with an average of $1.25 \mu \mathrm{m}$ (Fig. 2a). Some organisms, however, possessed numerous curly pili, granular in appearance and up to $7 \mathrm{~nm}$ in width, arranged closely around the bacterial surface (Fig. 2b).

Table 2 Pili on Legionella pneumophila after cultivation in vitro

\begin{tabular}{|c|c|c|c|}
\hline \multirow[t]{2}{*}{ Culture medium } & \multirow{2}{*}{$\begin{array}{l}\text { Incubation period } \\
\text { (days) }\end{array}$} & \multicolumn{2}{|c|}{ Serogroup } \\
\hline & & 1 & 23456 \\
\hline $\begin{array}{l}\text { Enriched blood agar } \\
\text { Enriched broth medium }\end{array}$ & $\begin{array}{l}2-3 \\
3-5\end{array}$ & $\begin{array}{l}7(16) \\
6(16)\end{array}$ & $\begin{array}{lllll}1 & 1 & 1 & 0 & 0 \\
1 & 1 & 1 & 0 & 0\end{array}$ \\
\hline
\end{tabular}

Numbers in parentheses indicate number of strains tested; serogroups 2-6 one strain of each examined.

\section{Discussion}

Examination by negative stain electron microscopy of strains of $L$. pneumophila, representing the six known serotypes of the organism, have shown these bacteria to possess both flagella and pili. From earlier reports, ${ }^{1415}$ failure to note these appendages was due, in part at least, to the composition of the initial bacteriological culture media. With changes of media, which resulted in a more rapid growth of the organisms, flagella and pili were readily observed. Similarly, for organisms other than legionellae both the incidence and orientation of flagella and pili vary with the culture media used, ${ }^{11} 16$ 

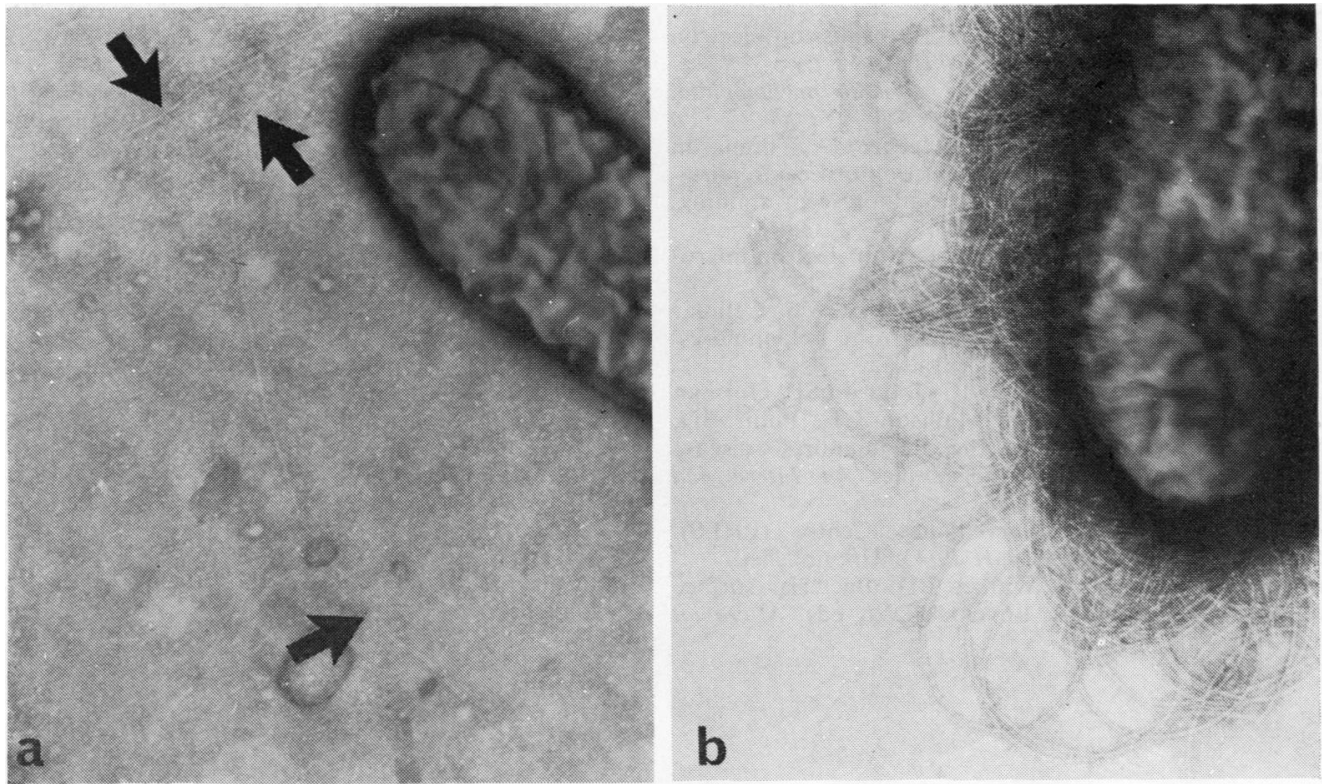

Fig. 2 Pili on Legionella pneumophila, grown on enriched blood agar, negatively stained with $1 \%$ phosphotungstic acid, pH 6.5. (a) Part of Bloomington 2 organism showing fine straight pili (arrows). ( $\times 52$ 000). (b) Region of Togus 1 organism with masses of granular, curly pili. $(\times 60000)$.

In Gram-negative bacteria, the flagellum is linked to the inner and outer membranes of the bacterial cell wall by means of the basal granule comprising a hook-like structure and four protein rings, one of which is incorporated into the peptidoglycan layer of the cell wall. ${ }^{16}$ That peptidoglycan is present in legionellae, though in a barely discernible form, ${ }^{5}$ has been questioned. The presence of flagella with an attachment mechanism similar to that for other Gram-negative organisms adds further evidence to the existence of this cell wall component.

Though the epidemiology of sporadic cases of Legionnaires' disease is not clear, there is evidence that the organism is present in the environment, particularly in water. It has been found in cooling tower water and streams in the USA ${ }^{9}$ and in bathroom showers in the UK. ${ }^{10}$ If the organism exists primarily in water, and its pathogenicity for man is coincidental, the production of flagella under suitable cultural conditions is not unexpected. Failure to observe flagella or pili in organisms from clinical material may reflect the advanced phase of bacterial replication, for example within the lung, a modification to the organism cell wall, or conditions in vivo adverse to flagella production. That pili were observed only on strains grown on enriched blood agar and in broth medium is not surprising, since this type of appendage, thought to be an integral cell wall component, ${ }^{11}$ is found on many species in the logarithmic phase of growth and disappears thereafter. ${ }^{11}$ Although flagella and pili were not found in clinical specimens, it is possible that these antigens may play a part in stimulating antibodies in the early phase of disease during exponential growth of the bacteria in vivo.

The presence of such appendages on legionellae is very significant in the determination of the taxonomic relation of the new group to other bacterial species. Cultural and structural studies are in progress to characterise these remarkable microorganisms further.

We thank Mrs Joan Casson for help in preparing the electron micrographs.

\section{References}

${ }^{1}$ Brenner DJ, Steigerwalt AG, McDade JE. Classification of the Legionnaires' disease bacterium: Legionella pneumophila, genus novum, species nova, of the family Legionaceae familia nova. Ann Intern Med 1979;90:1218-20.

2 Frazer DW, Tsai TR, Orenstein W, Parkin WE, Beecham HJ, Shanar RG, Harris J, Mallison GF, Martin SM, McDade JE, Shepard CC, Brachman PS, and the Field Investigation Team. Legionnaires' disease. Description of an epidemic of pneumonia. N Engl J Med 1977;297: 1189-97.

${ }^{3}$ Rodgers FG, Macrae AD, Lewis MJ. Electron microscopy of the organism of Legionnaires' disease. Nature 1978; 272:825-6.

4 Chandler FW, Cole RM, Hicklin MD, Blackmon JA, 
Callaway CS. Ultrastructure of the Legionnaires' disease bacterium. A study using transmission electron microscopy. Ann Intern Med 1979;90:642-7.

${ }^{5}$ Rodgers FG. Ultrastructure of Legionella pneumophila. $J$ Clin Pathol 1979;32:1195-202.

${ }^{6}$ Cherry WB, Pitman B, Harris PP, Hebert GA, Thomason BM, Thacker L, Weaver RE. Detection of Legionnaires' disease bacteria by direct immunofluorescent staining. J Clin Microbiol 1978;8:329-38.

' Rodgers FG, Macrae AD. Immunoferritin electron microscopy in legionellosis. Lancet $1979 ; \mathrm{i}: 786$.

${ }^{8}$ Moss CW, Weaver RE, Dees SB, Cherry WB. Cellular fatty acid composition of isolates from Legionnaires' disease. J Clin Microbiol 1977;6:140-3.

- Morris GK, Patton CM, Feeley JC, Johnson SE, Gorman G, Martin WT, Skaliy P. Mallison GF, Politi BD, Mackel DC. Isolation of the Legionnaires' disease bacterium from environmental samples. Ann Intern Med 1979;90:664-6.

${ }^{10}$ Communicable Disease Surveillance Centre (PHLS). Communicable Disease Report 79/43. Unpublished.

${ }^{11}$ Hodgkins W, Short JA, Walker PD. Bacterial surface structures. In: Fuller R, Lovelock DW, eds. Microbial
Ultrastructure. The Use of the Electron Microscope. London: Society for Applied Bacteriology Technical series No. 10, 1976:49-71.

${ }^{12}$ Feeley JC, Gorman GW, Gibson RJ. Primary isolation media and methods. In: Jones GL, Hebert GA, eds. Legionnaires' the Disease, the Bacterium and Methodology. Atlanta, Georgia: Centre for Disease Control, 1978:107-17.

${ }^{13}$ Greaves PW, Sharp GB, Macrae AD. Isolation of Legionella pneumophila. Lancet 1979; $1: 551-2$.

14 Thomason BM, Chandler FW, Hollis DG. Flagella on Legionnaires' disease bacteria: an interim report. Ann Intern Med 1979;91 :224-6.

15 Rodgers FG, Greaves PW, Macrae AD. Flagella and fimbriae on legionella organisms. Lancet 1979;ii:753-4.

${ }^{16}$ Silverman M, Simon MI. Bacterial flagella. In: Stan MP, Ingram JL, Balow A, eds. Ann Rev Microbiol 1977;31: 397-419.

Requests for reprints to: Dr FG Rodgers, Public Health Laboratory, University Hospital, Queen's Medical Centre, Nottingham NG7 2UH. 